\title{
Cellular vaccines in listeriosis: role of the Listeria antigen GAPDH
}

\author{
Ricardo Calderón-González ${ }^{1,2+}$, Elisabet Frande-Cabanes ${ }^{1+}$, Lucía Bronchalo-Vicente ${ }^{1,3}$, \\ M. Jesús Lecea-Cuello ${ }^{4}$, Eduardo Pareja ${ }^{5}$, Alexandre Bosch-Martínez ${ }^{1}$, Mónica L. Fanarraga ${ }^{2}$, \\ Sonsoles Yañez-Díaz ${ }^{1,3}$, Eugenio Carrasco-Marín ${ }^{4 \neq}$ and Carmen Álvarez-Domínguez ${ }^{1 * \neq}$ \\ Grupo de Genómica, Proteómica y Vacunas, Primera Planta-Laboratorio 124, Fundación Marqués de Valdecilla-IFIMAV, Santander, Spain \\ ${ }^{2}$ Departamento de Biología Molecular, Facultad de Medicina, Universidad de Cantabria, Santander, Spain \\ ${ }^{3}$ Servicio de Dermatología, Hospital Universitario Marqués de Valdecilla, Santander, Spain \\ ${ }^{4}$ Servicio de Pediatría, Hospital Universitario Marqués de Valdecilla-IFIMAV, Santander, Spain \\ ${ }^{5}$ Information Technologies Research Group, Era7 Bioinformatics, Granada, Spain
}

Edited by:

Stephanie M. Seveau, The Ohio

State University, USA

Reviewed by:

William Picking, Oklahoma State

University, USA

Jean-Pierre Gorvel, Centre National

de la Recherche Scientifique, France

\section{${ }^{*}$ Correspondence:}

Carmen Álvarez-Domínguez, Grupo de Genómica, Proteómica y

Vacunas, Instituto de Formación e

Investigación Marqués de Valdecilla,

Avda. Cardenal Herrera Oria, s/n.

39011 Santander, Spain

e-mail: calvarez@humv.es

${ }^{\dagger}$ Authors participated equally in this study.

${ }^{\ddagger}$ Directors participated equally in this study.
The use of live Listeria-based vaccines carries serious difficulties when administrated to immunocompromised individuals. However, cellular carriers have the advantage of inducing multivalent innate immunity as well as cell-mediated immune responses, constituting novel and secure vaccine strategies in listeriosis. Here, we compare the protective efficacy of dendritic cells (DCs) and macrophages and their safety. We examined the immune response of these vaccine vectors using two Listeria antigens, listeriolysin O (LLO) and glyceraldehyde-3-phosphate-dehydrogenase (GAPDH), and several epitopes such as the LLO peptides, LLO $189-201$ and LLO91-99 and the GAPDH peptide, GAPDH $1-22$. We discarded macrophages as safe vaccine vectors because they show anti-Listeria protection but also high cytotoxicity. DCs loaded with $\mathrm{GAPDH}_{1-22}$ peptide conferred higher protection and security against listeriosis than the widely explored LLO91-99 peptide. Anti-Listeria protection was related to the changes in DC maturation caused by these epitopes, with high production of interleukin-12 as well as significant levels of other Th1 cytokines such as monocyte chemotactic protein-1, tumor necrosis factor- $\alpha$, and interferon- $\gamma$, and with the induction of $\mathrm{GAPDH}_{1-22}$-specific $\mathrm{CD}^{+}$ and $\mathrm{CD}^{+}$immune responses. This is believed to be the first study to explore the use of a novel GAPDH antigen as a potential DC-based vaccine candidate for listeriosis, whose efficiency appears to highlight the relevance of vaccine designs containing multiple $\mathrm{CD}^{+}$ and $\mathrm{CD}^{+}$epitopes.

Keywords: dendritic vaccines, Listeria monocytogenes, glyceraldehyde-3-phosphate-dehydrogenase

\section{INTRODUCTION}

Listeria monocytogenes is a Gram-positive pathogenic bacterium that is widely used as a vector for vaccines against other pathogens or in cancer therapy. However, because it is a human pathogen, it may cause life-threatening infections such as severe meningitis, encephalitis, and brain abscess in pregnant women, neonates, elderly people, and immunocompromised individuals. Vaccination is one of the most successful strategies to treat infectious diseases. However, in the case of listeriosis, there is no vaccine available for high-risk groups such as infants, pregnant women, or individuals with immunological impairment.

Current studies of prophylactic vaccines against L. monocytogenes focus on three strategies: (i) the creation of live attenuated pathogens able to access the cytosol and stimulate T cells, including the vaccine vectors with metabolically active but non-viable bacteria; (ii) the use of safe vectors with adjuvant properties able to induce strong immune responses; and (iii) the use of subunit vaccines containing bacterial antigens that might stimulate specific immune responses (Sashinami et al., 2003; Starks et al., 2004; Bruhn et al., 2007; Mohamed et al., 2012; Quispe-Tintaya et al., 2013). There is not a single ideal vector that might be considered safe for human trials, and the use of live vaccines in individuals with any type of immunosuppression poses severe difficulties. Safer vaccines such as subunit vaccines present the disadvantage of requiring strong adjuvants to potentiate their immune responses and these adjuvants might induce undesirable side effects in tissues.

Dendritic cells (DCs) show promise for use as prophylactic or therapeutic vaccine vectors in human trials (Martirosyan et al., 2012; Palucka and Banchereau, 2013; Yu et al., 2013). DCs play a major role in the development of cell-mediated immunity because they link innate and adaptive immune responses. They are powerful antigen-presenting cells (APCs) and have a distinct ability to prime naïve T helper (Th) T lymphocytes and cytotoxic T lymphocytes (CTLs). These features of DCs are responsible for their immunostimulatory potential. In fact, they have been used as cellular vaccines or adjuvants in immunotherapy against cancer or infections, such as listeriosis or aids (Pion et al., 2010; Kono et al., 2012; Vacas-Cordoba et al., 2013).

Macrophages are also efficient APCs and crucial cells for the innate and adaptive immune responses against listeriosis 
(Ziegler and Unanue, 1981; Portnoy et al., 2002; Pamer, 2004). In fact, L. monocytogenes natural habitats are the monocytes and macrophages, therefore, it seems likely that using these cells loaded with the pathogen might secrete unique antigens and generate protective immune responses. Macrophages infected with other bacteria such as Salmonella typhimurium or Mycobacterium tuberculosis have been successfully used as safe vaccines, conferring good protection against these pathogens (Sharma and Agrewala, 2004; Singh et al., 2011).

Murine L. monocytogenes infection is characterized by the development of a protective T-cell-dependent immunity mediated by both CD4 and CD8 T cells. Several T cell immunodominant epitopes restricted by MHC-I molecules have been reported such as the listeriolysin O (LLO) epitope $\mathrm{LLO}_{91-99}$ and the p60 epitope p60 $217-225$ (Sijts et al., 1996; Pamer, 2004). Less information is available concerning immunodominant CD4 epitopes restricted by MHC-II molecules, because only LLO epitope LLO $_{189-201}$ appears as immunodominant and p60 epitope p60301-312 as subdominant (Geginat et al., 2001). However, several other L. monocytogenes virulence factors such as ActA, MLP or glyceraldehyde-3-phosphate-dehydrogenase (GAPDH) (ÁlvarezDomínguez et al., 2008) appear to induce strong immune responses, and therefore, they might contain putative epitopes that confer protection against listeriosis. In this study, we examined the ability of a novel GAPDH peptide, $\mathrm{GAPDH}_{1-22}$ to confer protection against listeriosis when incorporated into macrophages or DCs as vaccine vectors. Our data showed that macrophages infected with $L$. monocytogenes were unsafe vaccine vectors, while $\mathrm{GAPDH}_{1-22}$-loaded DCs were safe and more efficient vaccine vectors against listeriosis than LLO91-99-loaded DCs.

\section{METHODS}

\section{ANIMALS}

We used C57BL/6 mice from our animal facilities at the University of Cantabria. Bone-marrow-derived macrophages (BMDMs) or bone-marrow-derived DCs were obtained from femurs of 8-12-week-old female mice. BMDMs or DCs were cultured at $2 \times 10^{6}$ cells $/ \mathrm{ml}$ in six-well plates in Dulbecco's Modified Eagle's Medium (DMEM) supplemented with 20\% fetal calf serum (FCS), $1 \mathrm{mM}$ glutamine, $1 \mathrm{mM}$ non-essential amino acids, $50 \mu \mathrm{g} / \mathrm{ml}$ gentamicin and $30 \mu \mathrm{g} / \mathrm{ml}$ vancomycin (DMEM complete medium) and $25 \mathrm{ng} / \mathrm{ml}$ macrophage colony-stimulating factor (M-CSF) for BMDMs or $25 \mathrm{ng} / \mathrm{ml}$ granulocyte-macrophage colony-stimulating factor (GM-CSF). On Day 7, the cells were harvested and analyzed by fluorescence-activated cell sorting (FACS) to evaluate cell surface markers and appropriate differentiation of BMDMs or DCs using the following markers: CD11bfluorescein isothiocyanate (FITC), CD11c-phycoerythrin (PE),

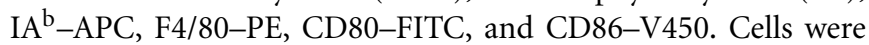
collected using cell scrapers for detaching adherent cells. In certain samples we also used after detaching adherent cells positive selection using anti-mouse CD11c-coated magnetic beads and MACSTM separation columns (Miltenyi Biotech Inc., Auburn, CA) on Day 7 as previously described (Kono et al., 2012).

\section{BACTERIA}

L. monocytogenes $10403 \mathrm{~S}$ strain (LM-WT) and the hly-deficient LM mutant (LM- $\triangle$ LLO, DPL-2161 strain) were obtained from D. A. Portnoy (University of California, Berkeley, CA, USA) and green fluorescent protein (GFP)-L. monocytogenes variant of the LM strain DH-L1039 (GFP-LM) was kindly provided by D. E. Higgins (Harvard Medical School, Boston, MA, USA).

\section{KINETIC INFECTION ASSAYS}

Differentiated BMDMs or DCs were cultured in 96-well plates at $1 \times 10^{6}$ cells $/ \mathrm{ml}$ and infected with LM-WT or LM- $\Delta$ LLO at a ratio of 10: 1 (bacteria: cells) as previously reported for different times $(0,4,8$, or 16h) (Prada-Delgado et al., 2001). CFU ratios are performed as reported and represented the ratio of CFU at $8 \mathrm{~h}$ to $\mathrm{CFU}$ at $0 \mathrm{~h} \pm S D$ of triplicates (Prada-Delgado et al., 2001; Carrasco-Marín et al., 2009).

\section{POSTNUCLEAR SUPERNATANT ISOLATION AND IMMUNOPRECIPITATION}

BMDMs and DCs were non-infected (NI) or infected with L. monocytogenes for $20 \mathrm{~min}$ (10:1; bacterium: cell ratio) and cells were homogenized in HBE buffer and postnuclear supernatants (PNSs) were obtained as previously reported (Álvarez-Domínguez and Stahl, 1999; Prada-Delgado et al., 2001; Del Cerro-Vadillo et al., 2006; Carrasco-Marín et al., 2009, 2011, 2012). Total membranes were pelleted from thawed PNSs after $35,000 \times g$ ultracentrifugation, as previously described (Carrasco-Marín et al., 2012). To detect LLO bound to MHC class II molecules, total membranes from PNSs were immunoprecipitated with mouse anti-IA ${ }^{\mathrm{b}}$ antibody (Y3P). Immunoprecipitates were run onto SDS-PAGE, transferred to nitrocellulose membranes and incubated with primary antibodies, rabbit anti-LLO or rabbit anti-GAPDH $\mathrm{G}_{1-22}$ and horseradishperoxidase-conjugated secondary antibodies.

\section{CONFOCAL MICROSCOPY}

BMDMs or DCs used for immunocytochemistry were cultured in 24-well plates with coverslips at $1 \times 10^{6}$ cells $/ \mathrm{ml}$ and infected with GFP-LM at a ratio of 10: 1 (bacteria: cells) for $1 \mathrm{~h}$. Cells were washed with PBS and fixed in 3\% paraformaldehyde. BMDMs or DCs were labeled with biotinylated anti-IA ${ }^{\mathrm{b}}$ antibody (40F monoclonal antibody) followed by TRICT-streptoavidin, CD11cPE or CD11b-PE, as previously described (Rodriguez-Del Rio et al., 2011; Frande-Cabanes et al., 2014). All confocal procedures with antibodies included a permeabilization treatment with PBS- $0.05 \%$ Triton X-100 as previously reported (Carrasco-Marín et al., 2012). Confocal microscopy imaging was performed with a Nikon A1R confocal microscope equipped with the laser lines: 405, 488, 514, 561, $638 \mathrm{~nm}$ using 60× Plan Apochromat VC 1.4 NA oil objective.

\section{PEPTIDES}

We used the following peptides, GAPDH ${ }_{1-22}, \mathrm{LLO}_{1-99}$, and LLO $_{189-201}$, the latter includes all MHC-II epitopes of LLO reported for $\mathrm{IA}^{\mathrm{b}}$ mouse haplotype, $\mathrm{LLO}_{189-200}$ and $\mathrm{LLO}_{190-201}$ (Ziegler and Unanue, 1981; Sijts et al., 1996; Geginat et al., 2001; Skoberne and Geginat, 2002; Carrero et al., 2012). All peptides were synthesized and purified by F. Roncal (CNB. CSIC. Madrid) 
after HPLC and Mass Spectrometry using a MALDI-TOF Reflex ${ }^{\mathrm{TM}}$ IV Bruker (Bruker Daltonics, Bremen, Germany) mass spectrometer. Peptide synthesis showed purity $>95 \%$ after HPLC and mass spectrometry.

\section{PREPARATION OF PEPTIDE-PULSED BMDMs OR DCs}

Differentiated and mature BMDMs or DCs were cultured in DMEM complete medium at a concentration of $2 \times 10^{6}$ cells $/ \mathrm{ml}$ and pulsed with $5 \mu \mathrm{M} \mathrm{LLO}_{91-99}, \mathrm{LLO}_{189-201}$, or $\mathrm{GAPDH}_{1-22}$ for $24 \mathrm{~h}$. Cells were washed twice in Hank's Balanced Salt Solution (HBSS), detached with cell scrapers and counted.

\section{VACCINATION PROTOCOLS}

Differentiated and matured BMDMs or DCs were cultured in six-well plates at $2 \times 10^{6}$ cells $/ \mathrm{ml}$ and incubated with different peptides, as described in the previous section. For BMDMs or DCs loaded with LM-WT vaccines, we infected cells with L. monocytogenes as above for $0 \mathrm{~h}$. Cells were washed and cultured in DMEM-2\% FCS and $20 \mu \mathrm{g} / \mathrm{ml}$ gentamicin for $24 \mathrm{~h}$. Cells were washed with HBSS, detached with cell scrapers, washed three times, counted, and cell pellets were resuspended at $1 \times 10^{6}$ cells $/ \mathrm{ml}$ in DMEM-20 $\mu \mathrm{g} / \mathrm{ml}$ gentamicin. Different BMDM or DC vaccine vectors $\left(5 \times 10^{5}\right.$ cells/mice $)$ were inoculated in the peritoneal cavity of mice $(n=5)$ for 7 days or were non-vaccinated $(\mathrm{NV})$. In same controls, vaccinations were performed with peptides in solution $(5 \mu \mathrm{M})$ administrated similar to DC vaccines. All mice were inoculated with $10^{3}$ CFU L. monocytogenes i.p. for an additional 3 days. The vaccination timing followed similar protocols reported for studies using L. monocytogenes as a vaccine (Lauer et al., 2008; Rodriguez-Del Rio et al., 2011; Carrasco-Marín et al., 2012; Kono et al., 2012). Mice were bled before sacrifice and serum stored at $-80^{\circ} \mathrm{C}$ to measure cytokines by FACS analysis. Spleens and livers were homogenized and CFUs counted in homogenates.

\section{FACS ANALYSIS OF BMDMs, DCs, AND CYTOKINE MEASUREMENTS}

BMDMs or DCs were cell surface labeled with antibodies against the following markers: CD11b (for macrophages), CD11c (for DCs), F4/80 (for activated phagocytes), CD80 (for mature DCs), CD86 (for mature DCs) or IA ${ }^{\mathrm{b}}$ (MHC-II for C57BL/6 mice) and analyzed by FACS. Cytokines of vaccinated and NV mice were quantified by using the CBA kit (Becton Dickinson, Palo Alto, CA, USA). Samples were performed in triplicate and the results are the mean $\pm S D$ of two separate experiments. ANOVA was used for statistics with the cytokine measurements. Data were analyzed using the FlowJo software (Treestar, Ashland, OR).

\section{FACS ANALYSIS OF SPLEENS}

We used FACS analysis for cell surface labeling of spleen cells $\left(10^{5}\right.$ cells), using monoclonal antibodies FITC or APC-labeled (BD Biosciences, San Jose, CA, USA) against CD4 or CD8. Peptides used were $\mathrm{LLO}_{1-99}, \mathrm{LLO}_{189-201}$, or $\mathrm{GAPDH}_{1-22}$. For measuring intracellular IFN- $\gamma$, spleen cells were plated into 96-well round-bottom plates $\left(5 \times 10^{6}\right.$ cells $\left./ \mathrm{ml}\right)$ and stimulated with each of the $\mathrm{LLO}_{91-99}$, $\mathrm{LLO}_{189-201}$, or $\mathrm{GAPDH}_{1-22}$ peptides independently $\left(10^{-5} \mathrm{M}\right.$ each peptide) for $5 \mathrm{~h}$ in the presence of brefeldin A (intracellular cytokine staining), as described previously (Bahjat et al., 2008; Lauer et al., 2008; Rodriguez-Del Rio et al., 2011; Carrasco-Marín et al., 2012). Stimulated cells were surface stained for CD4 and CD8 and then fixed and permeabilized using a cytofix/cytoperm kit to measure intracellular IFN- $\gamma$ (BD Biosciences). Samples were acquired using a FACSCanto flow cytometer (BD Biosciencies). Data were gated to include exclusively $\mathrm{CD}^{+}{ }^{+}$or $\mathrm{CD}^{+}$events, and the percentages of these cells expressing IFN- $\gamma$ were determined according with the manufacturer's recommendations. Results of LLO-peptide-stimulated splenocytes were corrected according to the percentages of total $\mathrm{CD}^{+}{ }^{+}$and $\mathrm{CD}^{+}$cells. Data were analyzed using FlowJo software (Treestar, Ashland, OR, USA). To confirm the frequency of $\mathrm{LLO}_{91-99}$ - or GAPDH $\mathrm{G}_{1-22}$-specific CD8 T cells producing IFN- $\gamma$, we used recombinant soluble dimeric mouse $\mathrm{H}-2 \mathrm{~K}^{\mathrm{b}}: \mathrm{Ig}$ fusion protein following the instructions of the manufacturer (DimerX I; BD Bioscience). $\mathrm{LLO}_{91-99}$ or $\mathrm{GAPDH}_{1-22}$ peptides $(40 \mu \mathrm{M})$ were preincubated with $\mathrm{H}-2 \mathrm{~K}^{\mathrm{b}}: \mathrm{Ig}(1 \mu \mathrm{M})$ in PBS, at $37^{\circ} \mathrm{C}$ for $16 \mathrm{~h}$ and incubated with the staining cocktail mix containing PEconjugated A85-1 mouse monoclonal antibody (BD Biosciences) for $1 \mathrm{~h}$ at room temperature. Splenocytes $\left(2 \times 10^{7}\right.$ cells $\left./ \mathrm{ml}\right)$ were incubated with IFN- $\gamma$ and CD8 antibodies and the staining cocktail mix described above for $10 \mathrm{~min}$ at $4^{\circ} \mathrm{C}$. Percentages of $\mathrm{CD}^{+}$gated cells were expressed as the mean $\pm S D$ of triplicates $(P<0.05)$. Data were analyzed using FlowJo software.

\section{STATISTICAL ANALYSIS}

For statistical analysis, the Student's $t$-test was applied. ANOVA analysis was applied also for cytokine measurement. $P \leq 0.05$ was considered significant. GraphPad software was used for graphic presentation.

\section{ETHICS STATEMENT}

This study was carried out in strict accordance with the recommendations in the Guide for the Care and Use of Laboratory Animals of the Spanish Ministry of Science, Research and Innovation. The Committee on the Ethics of Animal Experiments of the University of Cantabria approved this protocol (Permit Number: 2012/06) that follows the Spanish legislation (RD $1201 / 2005)$. All surgery was performed under sodium pentobarbital anaesthesia, and all efforts were made to minimize suffering.

\section{RESULTS \\ PREPARATION OF BMDM AND DC VACCINE VECTORS INFECTED WITH LM}

To use BMDMs and DCs as vectors loaded with pathogenic L. monocytogenes, we first discarded any differences in BMDM and DC phagocytic parameters, balancing their differentiation and maturation states. We differentiated both cells with their corresponding growth factors, M-CSF or GM-CSF and checked their maturation states. All BMDM preparations

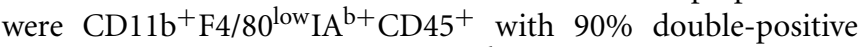

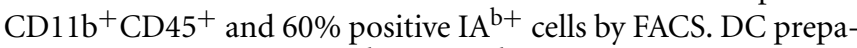
rations were $\mathrm{CD} 11 \mathrm{c}^{+} \mathrm{F} 4 / 80^{\text {low }} \mathrm{CD} 11 \mathrm{~b}^{\text {low }} \mathrm{IAb}^{+}$with $95 \%$ positive $\mathrm{CD}_{11 c^{+}}$and $70 \%$ positive $\mathrm{IA}^{\mathrm{b}+}$ cells.

We examined whether L. monocytogenes was able to infect both cells with similar kinetics. Infection of BMDMs with pathogenic L. monocytogenes (LM-WT) showed a characteristic exponential proliferation of $4 \mathrm{~h}$ duration that ended in a plateau phase of 
growth at $16 \mathrm{~h}$ post-infection. However, LM-WT growth in DCs remained exponential even at $16 \mathrm{~h}$ post-infection (Figure 1A, black circles). Listericidal phagocytes degraded L. monocytogenes within the phagosomal environment.
To compare the listericidal abilities of both BMDMs and DCs, we used a L. monocytogenes hly-deficient strain (LM- $\Delta$ LLO) with a known gene deletion that rendered it unable to escape from phagosomes. BMDMs and DCs had similar listericidal activity,

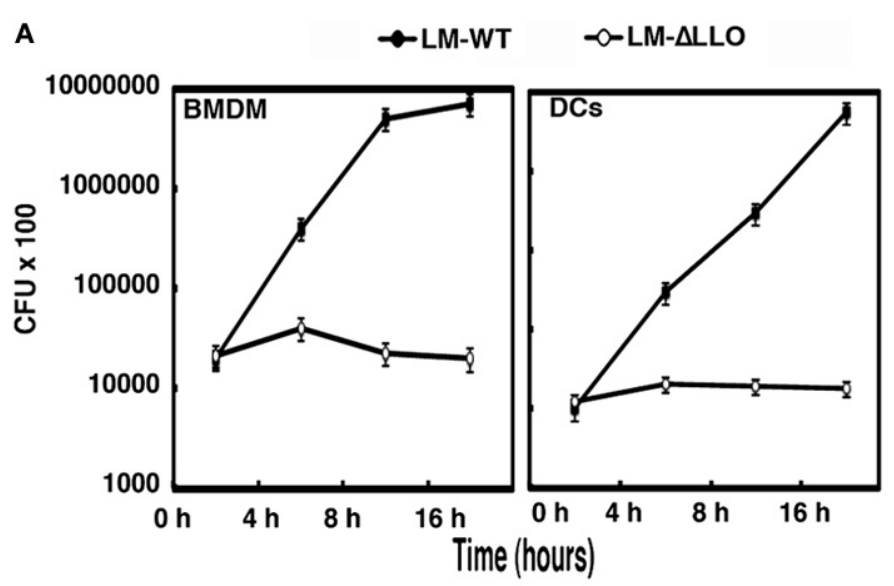

B

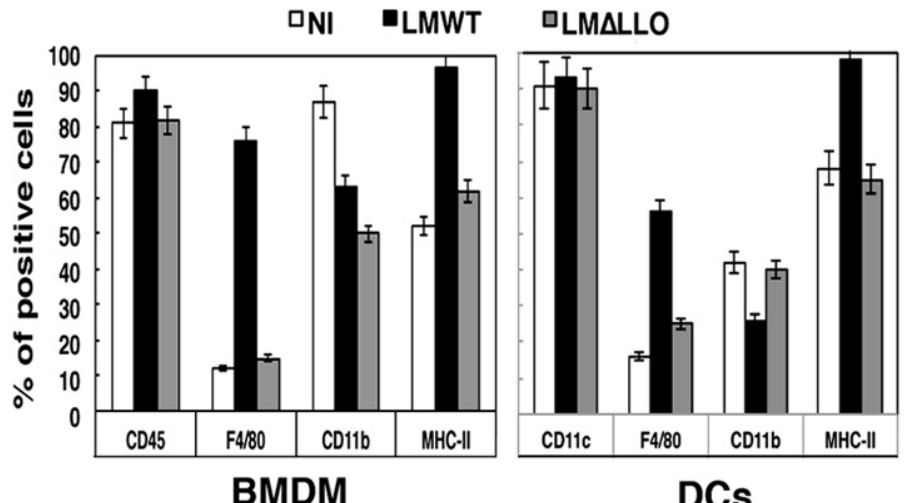

C

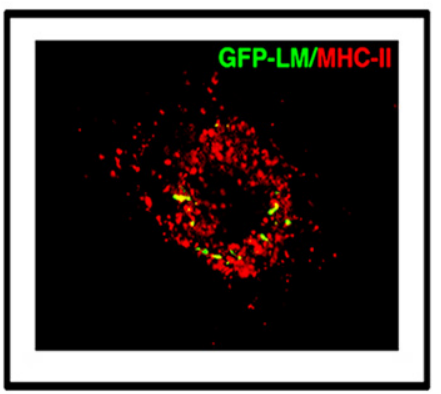

BMDM

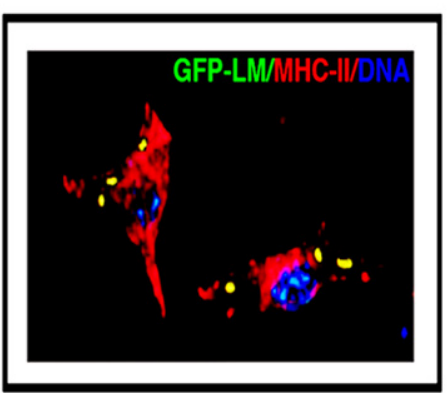

DCs
FIGURE 1 | BMDM and DC vaccines infected with different

L. monocytogenes strains. (A) Kinetic analysis of murine BMDMs and DCs infected with LM-WT or LM- $\Delta$ LLO. Results are expressed as CFU (mean $\pm S D$ ) obtained with triplicate samples from three independent experiments (main differences are observed between LM-WT and LM- $\Delta$ LLO results, $P<0.05)$. (B) BMDMs or DCs were infected with LM-WT or LM- $\Delta$ LLO (10:1 ratio of bacteria: cells) for $2 \mathrm{~h}$ or were non-infected (NI), detached from plates, washed several times, and surface stained with the following FITC- or PE-labeled antibodies: CD45-FITC, F4/80-PE, CD11b-APC, CD11c-PE, or anti-IA ${ }^{b}-A P C$. Samples were acquired using a FACSCanto flow cytometer and percentages of positive cells for each antibody are shown. Results are expressed as the mean $\pm S D$ of triplicate samples $(P<0.05)$. (C) Images correspond to confocal microscopy projections of BMDMs or DCs infected with GFP-LM (green channel), anti-MHC-II antibodies that label the antigen-processing compartments (Y3P biotinylated antibody followed by goat anti-mouse TRITC labeled) (red channel) and DNA (blue channel). Colocalization of GFP-LM and MHC-II (yellow fluorescence) is observed in BMDMs and DCs images. All BMDM preparations were $\mathrm{CD} 11 \mathrm{~b}^{+} \mathrm{CD} 45^{+} \mathrm{F} 4 / 80^{\text {high }} \mathrm{MHC}-$ II $^{\text {high }}$, reflecting their macrophage origin and purity and DC preparations were $\mathrm{CD} 11 \mathrm{C}^{+} \mathrm{F} 4 / 80^{\text {high }} \mathrm{CD} 11 \mathrm{~b}^{\text {low }} \mathrm{MHC}-\mathrm{II}^{\text {high }}$, reflecting their DC origin and purity. 
because LM- $\triangle$ LLO strain did not replicate in BMDMs or DCs (Figure 1A, white circles). Activation of phagocytes seems to be a prerequisite to trigger a powerful and protective immune response against L. monocytogenes. High percentages of positive $\mathrm{MHC}-\mathrm{II}^{+}$and $\mathrm{F} 4 / 80^{+}$cells are characteristics of activated phagocytes. Infection with LM-WT increased the number of positive cells for MHC-II and F4/80 in BMDMs and DCs, showing 95-100\% positive IA $^{\mathrm{b}}$ cells in both cell types (Figure 1B, white bars). However, the number of positive cells of markers not involved in activation such as CD11b for BMDMs or CD11c for DCs was not increased but diminished (Figure 1B, black bars). LM- $\Delta$ LLO strain infection caused no modification in the number of positive $\mathrm{MHC}-\mathrm{II}^{+}$or $\mathrm{F} 4 / 80^{+} \mathrm{BMDMs}$ or DCs (Figure 1B, gray bars). In summary, the phagocytic features of BMDMs and DCs infected with LM-WT appeared similar but clearly different than when these cells were infected with LM- $\Delta$ LLO. This prompted us to discard the use of LM- $\Delta$ LLO mutants in cellular vaccination.

We measured the ability of phagosomes to transform into antigen-processing compartments or MIIC using a method that colocalized GFP-LM-WT with MHC-II molecules in BMDMs and DCs infected with L. monocytogenes (Carrasco-Marín et al., 2011). Analysis of confocal images indicated significant colocalization of GFP-LM with MHC-II molecules in BMDMs and DCs (yellow fluorescence in Figure 1C). CD11b or CD11c molecules, not involved in antigen presentation and in the case of CD11c with a preferential surface pattern, did not colocalize with GFP-LM (data not shown). BMDMs and DCs showed similar GFP-LM colocalization with MHC-II molecules, 70 and $72 \%$ rates of colocalization, respectively. In summary, BMDMs infected with LM-WT showed similar phagocytic, activation and antigen processing features as DCs.

\section{SELECTION OF L. MONOCYTOGENES ANTIGENS TO EVALUATE PRIMARY T CELL RESPONSES AFTER VACCINATION WITH BMDMS AND DCs}

LLO appears as the immunodominant antigen that elicits specific $\mathrm{T}$ cell responses in listeriosis (Geginat et al., 2001; Skoberne and Geginat, 2002; Pamer, 2004; Bruder et al., 2005; Carrero et al., 2012). Studies from our group have also characterized a novel L. monocytogenes antigen, GAPDH that generates peptiderestricted antibodies in the absence of adjuvants, suggesting the induction of strong $\mathrm{T}$ cell responses (Álvarez-Domínguez et al., 2008). First, we verified that LLO and GAPDH generated specific T cells responses with similar efficiencies. Macrophages and DCs are the main APCs in lymph nodes able to stimulate T cells. We immunized the hind footpads of mice with a bacterial lysate (LM-lysate) in the absence of adjuvants as described previously (Mohamed et al., 2012) and recovered the popliteal lymph nodes to evaluate specific $\mathrm{T}$ cell responses to different antigens in vitro. $\mathrm{T}$ cell responses were dose dependent, similar for purified LLO, GAPDH or L. monocytogenes lysates, and had a significant peak at $50 \mu \mathrm{M}$ concentrations (Figure 2B). Therefore, immunization with bacterial lysates generated LLO- and GAPDH-specific T cells in similar ranges. These results strongly suggested that macrophages and DCs in vivo processed LLO and GAPDH with similar efficiencies, since their $\mathrm{T}$ cell responses were comparable or even slightly enhanced with GAPDH (gray bars in Figure 2A). We also confirmed antigen processing efficiency after immunoprecipitation of MHC-II molecules from total membranes of BMDM and DCs infected with LM-WT. We recovered LLO and GAPDH bound forms to MHC-II molecules as previously reported (Carrasco-Marín et al., 2012) (data not shown).

We compared the surface expression patterns of BMDMs or DCs loaded with purified LLO or GAPDH, or after infection with LM-WT. We prepared BMDMs and DCs followed by infection with LM-WT (bacteria: cells ratio, 10:1) (BMDMLM-WT or DC-LM-WT) or loaded with $50 \mu \mathrm{M}$ purified LLO (BMDM-LLO or DC-LLO) or GAPDH (BMDM-GAPDH or DCGAPDH) for 16 h. BMDM-LLO, DC-LLO, BMDM-GAPDH, and DC-GAPDH showed an increase in the percentages of MHC$\mathrm{II}^{+}$positive cells, similar to the enhancement observed with DC-LM-WT. However, DC-LLO or DC-GAPDH caused no significant modification in the numbers of positive $\mathrm{CD}_{11 \mathrm{~b}}{ }^{+}$or CD11c ${ }^{+}$cells (Table 1). These data suggest that DC-LM-WT, DC-LLO, and DC-GAPDH showed similar percentages of positive $\mathrm{MHC}-\mathrm{II}^{+}$cells that might correspond to mature DCs and not to immature DC. Incubation of DC with certain peptides was previously reported to cause similar DC maturation (Pion et al., 2010; Kono et al., 2012).

Widely characterized LLO immunodominant $\mathrm{CD}^{+}$and $\mathrm{CD}^{+}{ }^{+}$epitopes are: $\mathrm{CD}^{+}{ }^{+}$-restricted $\mathrm{LLO}_{91-99}$ peptide that binds to MHC-I molecules ( $\mathrm{Kb}, \mathrm{Kd}$, or $\mathrm{Ld})$ and $\mathrm{CD}^{+}{ }^{-}$-restricted LLO $_{189-201}$ peptide that binds to MHC-II molecules (IA ${ }^{\mathrm{b}}$ ) (Geginat et al., 2001; Skoberne and Geginat, 2002; Bruder et al., 2005). No information on GAPDH immunodominant $\mathrm{CD}^{+}$or $\mathrm{CD}^{+}$epitopes is available, therefore, we performed prediction analysis on the binding abilities of $\mathrm{GAPDH}_{1-22}$ to $\mathrm{MHC}-\mathrm{I}$ or MHC-II molecules using a prediction method with the IEDB analysis resource Consensus tool (Kim et al., 2012), which combines predictions from ANN (Nielsen et al., 2003; Lundegaard et al., 2008), SMM (Peters and Sette, 2005), and Comblib (Sidney et al., 2008). We also included in this analysis $\mathrm{LLO}_{91-99}$ and LLO $189-201$ peptides because these epitopes were eluted from MHC-I and MHC-II molecules, respectively, and their binding affinities are known (Geginat et al., 2001; Skoberne and Geginat, 2002) (Table 2). IEDB analysis predicted that good binders showed percentile ranks $<10$, while weak binders showed percentile ranks $<100$. $\mathrm{GAPDH}_{1-22}$ peptide was a strong binder to MHC-I molecules, similar to $\mathrm{LLO}_{91-99}$. The following GAPDH sequences showed the highest affinities, $\mathrm{GAPDH}_{5-15}$ with a 1.60 percentile rank and $\mathrm{GAPDH}_{8-18}$ with a 2.3 percentile rank, compared with a 1.80 percentile rank for $\mathrm{LLO}_{91-99}$ (Table 2, MHC-I binding values). With regards to binding to MHC-II molecules, it seems that $\mathrm{GAPDH}_{1-22}$ peptide and $\mathrm{LLO}_{189-201}$ were weak binders, with percentile ranks of 74 . The GAPDH sequence with the lower percentile ranks was $\mathrm{GAPDH}_{4-18}$ with 69.15. $\mathrm{GAPDH}_{8-22}$ showed percentile ranks similar to LLO $_{189-201}$ (Table 2, MHC-II binding values). When we applied these data to the bioinformatics modeling of $\mathrm{GAPDH}_{1-22}$ and LLO 3D structures (Figures 2C,D), LLO $_{189-201}$ presented an $\alpha$ helix type 3D structure, while $\mathrm{LLO}_{91-99}$ peptide had a loop structure (Figure 2D). GAPDH $_{5-15}$ also appeared as a loop $3 \mathrm{D}$ structure (Figure 2C, pink in $3 \mathrm{D}$ model) and $\mathrm{GAPDH}_{8-22}$ showed an $\alpha$-helix 3D structure (Figure 2C, yellow in 3D model). The theoretical 3D predictive model for Listeria monocytogenes GAPDH was produced using the Automated Comparative Protein 


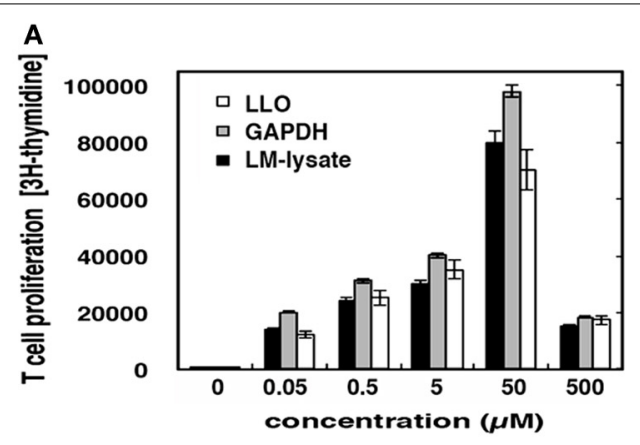

C

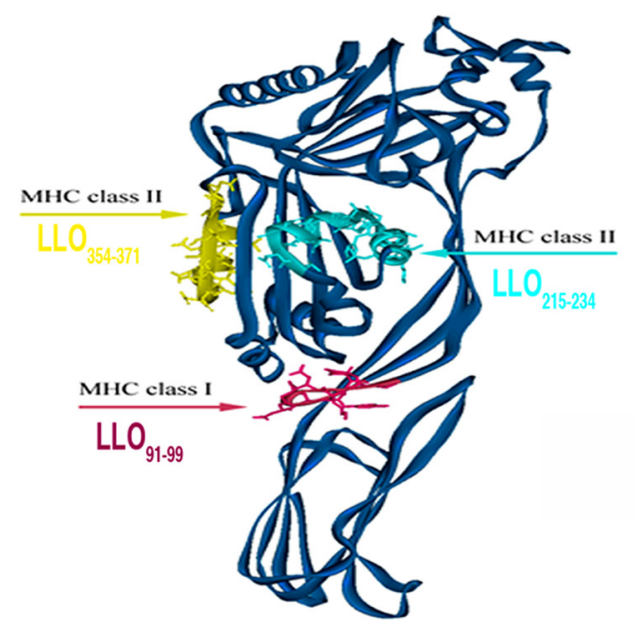

FIGURE 2 | Selection of L. monocytogenes antigens to evaluate primary $T$ cell responses after vaccination with BMDMs and DCs. (A) Thirty micrograms of total membranes of BMDMs or DCs infected with L. monocytogenes was immunoprecipitated with mouse anti-MHC-II, and subjected to western blotting with rabbit anti-LLO (upper lanes) or rabbit anti-GAPDH ${ }_{1-22}$ (lower lanes). NI lanes correspond to non-infected BMDMs or DCs. (B) $T$ cell proliferation of
B

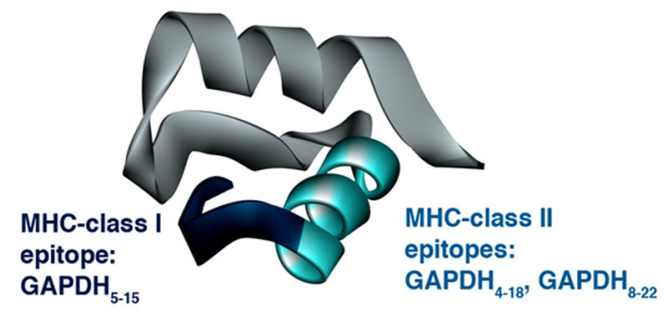

D
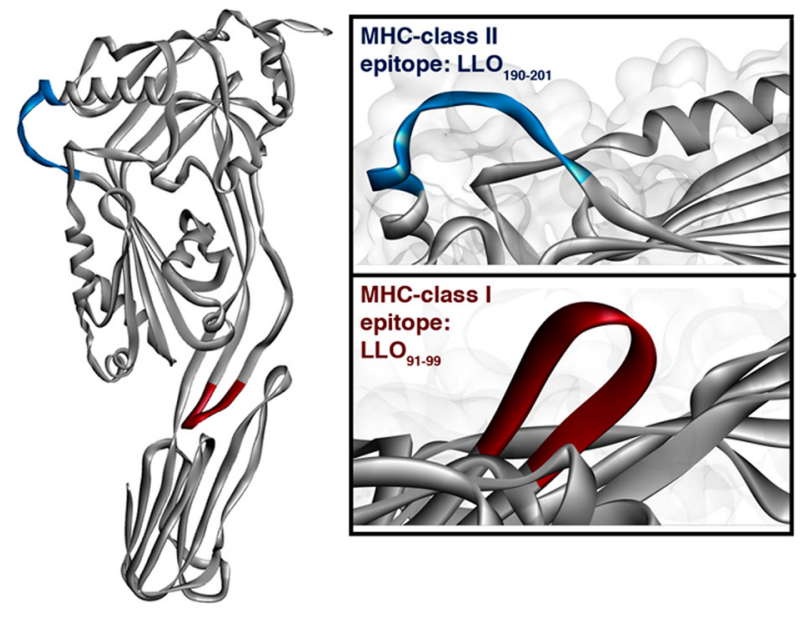

homogenates of popliteal lymph nodes after hind foot pad inoculation with $30 \mu \mathrm{g}$ LM-lysate. Cells were stimulated with LLO, GAPDH, or LM-lysate. Results show $\left[{ }^{3} \mathrm{H}\right]$-thymidine incorporation in triplicate samples of $T$ cells. (C) $3 D$ model of $G_{A P D_{1-22}}$ peptide showing the $\mathrm{MHC}-\mathrm{I}$ binding sequences in pink and the $\mathrm{MHC}-\mathrm{Il}$ binding sequences in yellow. (D) 3D structure of LLO showing the MHC-I and MHC-II epitopes in the C57BL/6 mouse model.
Modeling Server SWISS-MODEL available at: (http://www. expasy.ch/swissmod/SWISS-MODEL.html). Therefore, it seems that $\mathrm{GAPDH}_{1-22}$ peptide might contain at least two MHC-I binding sequences as well as two MHC-II binding sequences in the C57BL/6 mouse model. Taken together, these results indicate that LLO and GAPDH, as well as their epitopes, are good candidates to include in cellular vaccine designs against listeriosis.

\section{COMPARISON OF DIFFERENT BMDM AND DC VACCINE VECTORS FOR PROTECTION AGAINST LISTERIOSIS}

As a first approach using cellular vaccine vectors against listeriosis, we prepared different BMDM and DC vaccine vectors containing LM-WT, LLO, or GAPDH, and used them in vaccination protocols against an $L$. monocytogenes challenge of $5 \times 10^{3}$ bacteria/mice $(n=5)$, inoculated for 3 days. We also tested the in vitro cytotoxicity of these vaccine vectors using a hemolysis assay with sheep-red blood cells, SRBC. Although BMDMs infected with LM-WT showed a good protection range, they also showed a high level of hemolysis ( $\sim 70 \%)$. Two of five mice vaccinated died and showed hemolyzed livers (data not shown). BMDMs loaded
Table 1 | Surface markers of different BMDM and DC vaccine vectors.

\begin{tabular}{llllll}
\hline & \multicolumn{2}{c}{ BMDM1 } & & \multicolumn{2}{c}{ DC } \\
\cline { 2 - 3 } \cline { 6 - 6 } & CD11b & MHC-II & & CD11c & MHC-II \\
\hline NI & $87 \pm 1.5$ & $62 \pm 1.2$ & & $87 \pm 1.3$ & $72 \pm 1.3$ \\
LM-WT & $73 \pm 1.3$ & $90 \pm 2.0$ & & $98 \pm 1.5$ & $92 \pm 1.4$ \\
LLO & $70 \pm 1.2$ & $92 \pm 1.9$ & & $87 \pm 1.6$ & $92 \pm 1.5$ \\
GAPDH & $73 \pm 1.3$ & $92 \pm 1.8$ & & $89 \pm 1.7$ & $92 \pm 1.6$ \\
\hline
\end{tabular}

BMDMs and DCS were infected with LM-WT (10:1 ratio of bacteria: cells) or incubated with $50 \mu \mathrm{g} / \mathrm{ml}$ purified LLO or GAPDH for $16 \mathrm{~h}$, detached from the plates, washed several times, and surface stained with the following FITC- or PE-labeled antibodies: CD11b-FITC, CD11C-PE, anti-IA $-A P C$. Samples were acquired using FACSCanto flow cytometer and percentages of positive cells for each antibody are shown. Results are expressed as the mean $\pm S D$ of triplicate samples. ( $\left.{ }^{1} P<0.05\right)$.

with LLO showed $~ 50 \%$ protection but also $30 \%$ hemolysis, and one of five vaccinated mice died and presented with a hemolyzed liver (Figure 3A, gray bars). BMDMs loaded with GAPDH lacked 
Table 2 | MHC-I and MHC-II binding force predictions for LLO and GAPDH epitopes.

\begin{tabular}{|c|c|c|c|}
\hline MHC-I binding & MHC-I allele & Percentile rank & Sequence \\
\hline \multirow[t]{3}{*}{$\mathrm{LLO}_{91-99}$} & $\mathrm{H}-2-\mathrm{Kd}$ & $1.8 *$ & Complete (GB) \\
\hline & H-2-Ld & 38.3 & \\
\hline & $\mathrm{H}-2-\mathrm{Kb}$ & 75.1 & \\
\hline \multirow[t]{3}{*}{$\mathrm{GAPDH}_{1-22}$} & $\mathrm{H}-2-\mathrm{Kb}$ & $1.6^{*}$ & $5-15^{*}$ \\
\hline & $\mathrm{H}-2-\mathrm{Ld}$ & 2.3 & 8-18 \\
\hline & $\mathrm{H}-2-\mathrm{Kd}$ & 4.7 & $8-16$ \\
\hline MHC-II binding & MHC-II allele & Percentile rank & Sequence \\
\hline LLO $_{190-201}$ & $\mathrm{H}-2-\mathrm{IAb}$ & $74.3^{*}$ & Complete (WB) \\
\hline \multirow[t]{7}{*}{$\mathrm{GAPDH}_{1-22}$} & $H-2-I A b$ & $69.15^{*}$ & $4-18 *$ \\
\hline & $H-2-I A b$ & 70.23 & 5-19 \\
\hline & $H-2-I A b$ & 70.91 & $2-16$ \\
\hline & $H-2-I A b$ & 71.11 & $3-17$ \\
\hline & $H-2-I A b$ & $74.95^{*}$ & $8-22 *$ \\
\hline & $\mathrm{H}-2-\mathrm{IAb}$ & 75.61 & $7-21$ \\
\hline & $\mathrm{H}-2-\mathrm{IAb}$ & 75.72 & $1-15$ \\
\hline
\end{tabular}

Predictions of binding of peptides to MHC molecules performed with the IEDB analysis source Consensus tool. The lower the percentile ranks obtained, the better the binders. GAPDH $1-22$ peptide was compared to the predictions of LLO91-99 binding to MHC-I molecules and LLO $189-201$ binding to MHC-II molecules.

${ }^{*}$ Comparative peptide sequence with similar binding percentiles as LLO peptides. GB, good binder; WB, weak binder.

cytotoxicity but their protection was low $(\sim 40 \%)$. We obtained the highest protection and the lowest cytotoxicity using DC-LLO or DC-GAPDH with 90-95\% protection. DCs infected with LMWT also showed good protection in the range of $65-70 \%$, with no cytotoxicity (Figure 3A, compare black and gray bars, respectively). These results revealed that BMDMs were unsafe vaccine vectors against listeriosis, because they resulted in high cytotoxicity, either containing LM-WT or purified LLO. DCs seemed to be the safest vaccine vectors, conferring the highest protection against listeriosis.

To examine whether DCs loaded with LLO or GAPDH epitopes might also confer protection against listeriosis, we prepared DC vaccines loaded with peptides, DC-LLO91-99, DC-LLO $_{189-201}$ or DC-GAPDH ${ }_{1-22}$, and compared them for protection with DCs loaded with an L. monocytogenes lysate (DCLM lysate). Peptides in solution administrated as DC vaccines showed no protection at all (data not shown). As shown in Figure 3B (left plot), DC-GAPDH ${ }_{1-22}$ showed the highest protection $(\sim 99 \%)$, followed by DC-LLO ${ }_{91-99}(\sim 94 \%)$ (Figure 3B, $\mathrm{GAPDH}_{1-22} / \mathrm{DC}$ and $\mathrm{LLO}_{91-99} / \mathrm{DC}$ bars in left plot). However, DC-LLO ${ }_{189-201}$ conferred little protection $(\sim 5 \%)$, comparable to DC empty vaccine vectors or mice inoculated with saline (Figure 3B, NV-DC bars in left plot). NV mice showed characteristic features of listeriosis, such as granulomatous lesions in the liver and splenomegalia (Figure 3B, NV-DC upper image). Vaccinated mice with DC-GAPDH ${ }_{1-22}$ showed a clear reduction in liver granulomatous lesions and presented normal size spleens (Figure 3B, DC-GAPDH ${ }_{1-22}$ image), similar to vaccination with
DC-LLO91-99 (Kono et al., 2012). To note that positive selection of differentiated DCs with anti-mouse CD11c-coated magnetic beads and MACSTM separation columns did not give better protection results than our method (data shown in legend of Figure 3).

Effective DCs vaccine vectors present high percentages of positive $\mathrm{CD}^{+} 0^{+}$or $\mathrm{CD}^{+} 6^{+}$cells as classical DC activation markers as previously reported for DCs incubated with certain peptides (Pion et al., 2010). Therefore, we evaluated whether the high efficiency of DC-LLO $91-99$ or DC-GAPDH ${ }_{1-22}$ might correspond with high numbers of positive cells for these DC activation markers. As it is shown in Figure 3B (right plot), only DC-LLO $91-99$ or DC-GAPDH ${ }_{1-22}$ showed an increase in the number of positive $\mathrm{CD}^{+} 0^{+}$or $\mathrm{CD}^{+} 6^{+}$cells, similar to percentages obtained with DCs loaded with lipopolysaccharide, LPS (DC-LPS), used as a positive control. We also observed that DC-GAPDH ${ }_{1-22}$ showed a decrease in the percentages of positive CD11c ${ }^{+}$cells, similar to the pattern of DC-LPS, while DC-LLO ${ }_{91-99}$ showed no modification on the percentages of positive CD11 ${ }^{+}$cells. A decrease in the number of positive CD11 $\mathrm{c}^{+}$cells in DCs appears linked to polarized DCs, as in the case of LPS-loaded DCs (Kono et al., 2012).

We confirmed whether the protection capacity of DC vaccine vectors was linked to Th1 cytokine production. As shown in Figure 3C, DC vaccine vectors conferring protection against listeriosis, such as DC-LM-WT, DC-LLO ${ }_{91-99}$ or DC-GAPDH DH-22, $_{1}$, produced high levels of interleukin (IL)-2 and IFN- $\gamma(570-589 \pm$ $0.9 \mathrm{pg} / \mathrm{ml}$, and NV mice basal levels, $0.5 \pm 0.02 \mathrm{pg} / \mathrm{ml})$ and significant levels of monocyte chemotactic protein (MCP)-1 and tumor necrosis factor (TNF)- $\alpha$. Mice vaccinated with DC-GAPDH ${ }_{1-22}$ produced significantly more IL-12 than those vaccinated with DC-LLO $91-99$ did. Production of IL-6 was significantly reduced after vaccination with DC-LLO ${ }_{91-99}$ or DC-GAPDH ${ }_{1-22}$, indicating that the classical acute inflammation in listeriosis was avoided with vaccination. Therefore, the vaccination efficiency of DC-GAPDH ${ }_{1-22}$ was related to high production of IL-12, as well as significant levels of other Th1 cytokines such as IFN- $\gamma$, MCP-1, and TNF- $\alpha$. We did not observe any production of IL-10 in DC-vaccinated mice.

Vaccine efficiency is also linked to DC ability to expand the immune response, stimulating different $\mathrm{T}$ cells, both CD4 and CD8 subsets. Therefore, we analyzed the spleens of mice vaccinated with DC-LLO $91-99$, DC-LLO $_{189-201}$, or DC-GAPDH $1-22$ for production of a primary $\mathrm{T}$ cell response. We observed $1.2 \pm$ $0.05 \%$ positive $\mathrm{CD}^{+}$-restricted $\mathrm{LLO}_{91-99}$ cells and IFN- $\gamma$ producers after vaccination with DC-LLO $91-99$. We also observed $0.75 \pm 0.02 \%$ positive $\mathrm{CD} 4^{+}$-restricted $\mathrm{LLO}_{189-201}$ cells and IFN$\gamma$ producers after vaccination with DC-LLO $189-201$. We observed $1.23 \pm 0.04 \% \mathrm{CD}^{+}{ }^{-}$-restricted $\mathrm{GAPDH}_{1-22}$ cells and IFN- $\gamma$ producers and $1.81 \pm 0.1 \% \mathrm{CD}^{+}$-restricted $\mathrm{GAPDH}_{1-22}$ cells and IFN- $\gamma$ producers (Figure 3D). These results suggested that although vaccination with DC-LLO $189-201$ induced a primary and specific $\mathrm{CD} 4{ }^{+} \mathrm{T}$ cell response, these vaccines did not confer any protection against listeriosis. Vaccination with DC-LLO91-99 induced a strong and specific $\mathrm{CD} 8^{+} \mathrm{T}$ cell response and conferred protection. Vaccination with DC-GAPDH $\mathrm{H}_{1-22}$ induced specific $\mathrm{CD}^{+}$and $\mathrm{CD}^{+} \mathrm{T}$ cell responses and was highly protective. 


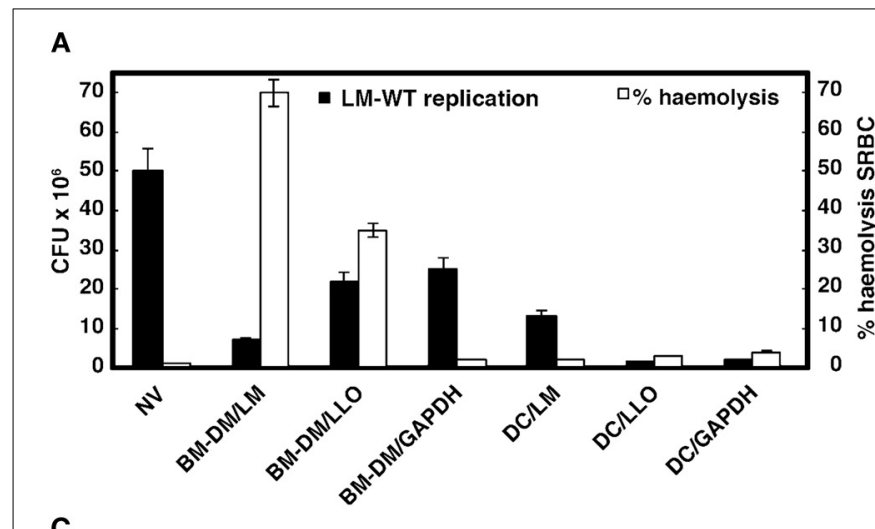

C

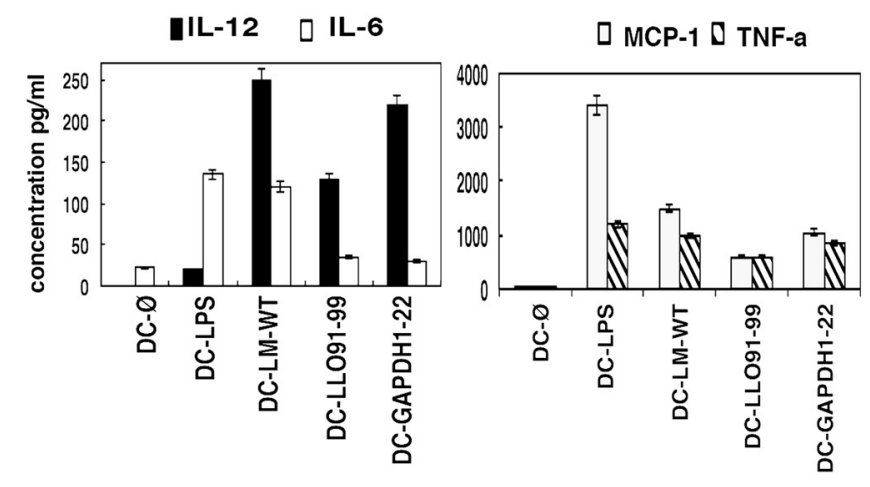

B

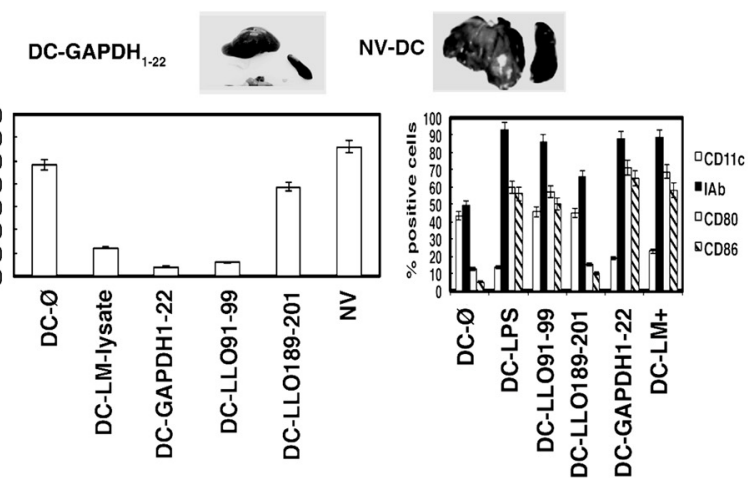

D
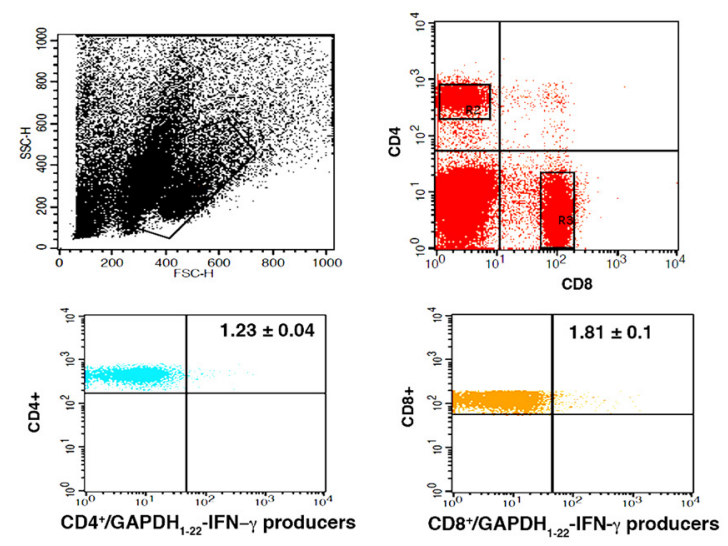

FIGURE 3 | Comparison of different BMDM and DC vaccine vectors for protection against listeriosis. (A) C57BL/6 mice were vaccinated i.p. or not (NV) for 7 days with different BMDM or DC vaccine vectors (BMDM-LM-WT, BMDM-LLO, BMDC-LM-WT, BMDC-LLO, and BMDC-GAPDH) $\left(1 \times 10^{6}\right.$ cells $)(n=5$ mice/vaccine vector $)$ and challenged i.p. with $5 \times 10^{3}$ CFU LM-WT for 3 days. Results of spleens homogenates are mean $\pm S D$ of three different experiments $(P<0.01)$ (black bars in figure and left scale legend). Same vaccine vectors were incubated in vitro with SRBC $(0.5 \%$ solution). Hemolytic units were defined as the dilution of the sample that caused $50 \%$ hemoglobin release from $200 \mathrm{ml}$ of $0.5 \%$ SRBC. Controls were established for $0 \%$ hemolysis using empty DCs and for $100 \%$ hemolysis by incubating SRBC with distilled water. (B) C57BL/6 mice were vaccinated i.p. or not with empty DCs (DC- $\varnothing$ ) or with saline (NV) using the vaccine vectors: DC-LM lysate, DC-GAPDH $1-22$, DC-LLO $_{189-201}$, DC-LLO $_{91-99 .}$. We also vaccinated with the following control vectors: DC-LMWT, DC-LPS-LLO ${ }_{91-99}$, and DC-LPS-GAPDH $1-22$ protection results were as follows: 70,92 , and $98 \%$. In several samples, positive selection of DC was performed with anti-mouse CD11c-coated magnetic beads and MACSTM separation columns, protection results of DC-LLO $91-99$ and DC-GAPDH ${ }_{1-22}$ after positive selection were as follows, 90 and $98 \%$, respectively. Left plot corresponds to results of spleens homogenates that are the mean $\pm S D$ of three different experiments $(P<0.05)$ Surface expression of different markers was analyzed by FACS in the prepared DC vaccine vectors. Samples were acquired using FACSCanto flow cytometer and percentages of positive cells for each antibody are shown. Results are expressed as the mean $\pm S D$ of triplicate samples $(P<0.05)$. (C) Cytokines were measured in serum from vaccinated and NV mice (DC- $\varnothing$ ) from (B). We also included another DC vaccine vector (DC-LPS) as a positive control. Levels of proinflammatory cytokines (MCP-1, TNF- $\alpha$, IFN- $\gamma$, IL-6, IL-12, or IL-10) were analyzed by using the CBA kit (Becton Dickinson) and flow cytometry. Results were expressed as cytokine concentration $(\mathrm{pg} / \mathrm{ml}$ of mean $\pm S D, P<0.05)$. IL-12 concentration for DC- $\varnothing$ vaccination was $8 \pm 0.03 \mathrm{pg} / \mathrm{ml}$ and for DC-LPS, $19 \pm 0.2 \mathrm{pg} / \mathrm{ml}$. IFN- $\gamma$ concentrations of samples were as follows: DC-LLO $_{91-99}(389 \pm 12 \mathrm{pg} / \mathrm{ml})$, DC-GAPDH ${ }_{1-22}(425 \pm 11 \mathrm{pg} / \mathrm{ml})$, DC-LMWT $(178 \pm 10 \mathrm{pg} / \mathrm{ml})$, DC-LPS $(200 \pm 0.3 \mathrm{pg} / \mathrm{ml})$. (D) Spleen cells obtained from homogenates after vaccination were stimulated for $5 \mathrm{~h}$ with $\mathrm{GAPDH}_{1-22}$ in the presence of brefeldin $\mathrm{A}$ for intracellular cytokine staining. GAPDH-peptide-stimulated spleen cell surface was stained for CD4 or CD8 and fixed and permeabilized using a cytofix/cytoperm kit. Stimulated cells were surface stained for CD4 or CD8 using anti-CD4 ${ }^{+}$ FITC-labeled or anti-CD8 ${ }^{+}$APC-labeled and data gated to include exclusively $\mathrm{CD}^{+}$or $\mathrm{CD}^{+}$events, R2, and R3 gates, respectively. Flow histograms show the percentages of $\mathrm{GAPDH}_{1-22} / \mathrm{CD} 4^{+}$and IFN- $\gamma$ producers (lower left) and $\mathrm{GAPDH}_{1-22} / \mathrm{CD}^{+}$and IFN- $\gamma$ producers (lower right) (R2 and R3 gates). Experiments were performed in triplicate and results are expressed as the mean $\pm S D(P<0.05)$.
We confirmed the frequency of $\mathrm{LLO}_{91-99}$-specific and $\mathrm{GAPDH}_{1-22}$-specific $\mathrm{CD}^{+}{ }^{+} \mathrm{T}$ cells using $\mathrm{H} 2-\mathrm{K}^{\mathrm{b}}-\mathrm{LLO}_{91-99}$ or $\mathrm{H} 2-\mathrm{K}^{\mathrm{b}}-\mathrm{GAPDH}_{1-22}$ dimers by flow cytometry after vaccination with DC-LM-WT, DC-LLO ${ }_{91-99}$ or DC-GAPDH ${ }_{1-22}$. As shown in Table 3, the occurrence of $\mathrm{LLO}_{91-99}$-specific $\mathrm{CD} 8^{+}$cells producing IFN- $\gamma$ after vaccination with DC- $\mathrm{LLO}_{91-99}$ was $1.22 \%$ of positive gated cells, which was higher than the frequency observed with DC-LM-WT $(0.48 \%)(P<0.05)$. The occurrence of $\mathrm{GAPDH}_{1-22}$-specific $\mathrm{CD} 8{ }^{+}$cells was $4.02 \%$ of positive gated cells; which was higher than the frequency one observed with DC-LM-WT-vaccinated mice (1.53\%). Therefore, primary T cell responses highlighted the role of L. monocytogenes-specific CD8 ${ }^{+}$ 
Table 3 | Frequencies of $\mathrm{LLO}_{91-99-}$ and $\mathrm{GAPDH}_{1-22}$-specific $\mathrm{CD}^{+} \mathrm{T}$ cells induced by $\mathrm{DC}$ vaccines.

\begin{tabular}{|c|c|c|c|c|}
\hline Vaccination type & $\begin{array}{c}\% \text { Total } \\
\text { dimer-CD8/LLO } 91-99\end{array}$ & $\begin{array}{c}\% \text { Gated } \\
\text { dimer-CD8/LLO } 91-99\end{array}$ & $\begin{array}{c}\% \text { Total } \\
\text { dimer-CD8/GAPDH }{ }_{1-22}\end{array}$ & $\begin{array}{c}\% \text { Gated } \\
\text { dimer-CD8/GAPDH } \\
1-22\end{array}$ \\
\hline DC-LM-WT & $0.05 \pm 0.001$ & $0.48 \pm 0.01$ & $0.05 \pm 0.002$ & $1.53 \pm 0.02$ \\
\hline DC-LLO91-99 & $0.06 \pm 0.001$ & $1.22 \pm 0.02$ & NA & NA \\
\hline DC-GAPDH $_{1-22}$ & NA & NA & $0.16 \pm 0.001$ & $4.02 \pm 0.03$ \\
\hline
\end{tabular}

Splenocytes from vaccinated mice were incubated with recombinant dimeric $\mathrm{H}_{-2} \mathrm{~K}^{b}: \mathrm{Ig}$ fusion protein loaded with $\mathrm{LLO}_{91-99}$ or GAPDH $\mathrm{H}_{1-22}$ peptides. The staining cocktail contained the dimeric fusion protein loaded with the peptides, CD8 and IFN- $\gamma$ antibodies. CD8+ cells were gated for anti-IFN- $\gamma$ staining (\% Gated dimer-CD8) to calculate the frequencies of $C D 8^{+}-L_{2} O_{91-99}$ or $C D 8^{+}-G A P D H_{1-22}$ restricted cells and IFN- $\gamma$ producers. $p<0.05$

$\mathrm{T}$ cells to confer significant protection against listeriosis, while $\mathrm{CD}^{+} \mathrm{T}$ cells seemed to participate less in protection.

\section{DISCUSSION}

Recently, cell-based vaccines have received considerable impetus following their success against infectious diseases and cancer (Starks et al., 2004; Kim et al., 2009; Pion et al., 2010; Singh et al., 2011; Kono et al., 2012; Martirosyan et al., 2012; Matsumura et al., 2013; Quispe-Tintaya et al., 2013; VacasCordoba et al., 2013). In the case of listeriosis vaccination, the emphasis has been on recombinant vaccines using live attenuated pathogens, metabolically active but non-viable bacteria or nonpathogenic bacteria harboring virulence gene clusters, although some of them do not trigger strong innate immune responses and require adjuvants (Brockstedt et al., 2005; Bruhn et al., 2007; Mohamed et al., 2012). These recombinant vaccines might also present safety concerns because live vaccines if administered to immunocompromised individuals might cause cytotoxicity. However, cellular vaccines such as BMDMs or DCs, or subcellular vectors such as endosomes or phagosomes appear to be safer candidates to harbor L. monocytogenes antigens because the vaccinated individuals are not directly exposed to live bacteria (Sashinami et al., 2003; Rodriguez-Del Rio et al., 2011; Carrasco-Marín et al., 2012; Kono et al., 2012). Moreover, high phagocytic abilities and induction of strong innate and specific immune responses are features that make cellular vaccines attractive.

We have attempted to design novel cell-based vaccines for listeriosis lacking cytotoxicity and pathogenicity and showing high protective activity. For this purpose, we chose BMDMs and DCs as vaccine vectors against L. monocytogenes. In this regard, the features of the cellular vaccines conferring successful protection against listeriosis were high phagocytic activity and good antigen processing. We observed that BMDMs and DCs infected with LM-WT shared equivalent listericidal features, activation patterns, and antigen processing competency. Therefore, BMDMs and DCs showed similar L. monocytogenes growth kinetics and degradation of the hly-deficient mutant LM- $\Delta$ LLO. BMDMs were $\mathrm{CD} 11 \mathrm{~b}^{+} \mathrm{F} 4 / 80^{\text {high }} \mathrm{MHC}-\mathrm{II}{ }^{\text {high }}$ cells and DCs were $\mathrm{CD} 11 \mathrm{c}^{+} \mathrm{F} 4 / 80^{\text {high }} \mathrm{CD} 11 \mathrm{~b}^{\text {low }} \mathrm{MHC}-\mathrm{II}^{\text {high }}$ cells. BMDMs and DCs transformed L. monocytogenes phagosomes into MIIC compartments with similar ratios, showing 70-72\% colocalization of GFP-LM with MHC-II molecules. Unexpectedly, protection and cytotoxicity of these vaccine vectors were different. BMDMs showed protection ratios lower than those of
DCs and high cytotoxicity measured in vitro by SRBC hemolysis and in vivo by examining death in mice. Recently, LLO immunogenicity and cytotoxicity were dissociated, indicating that LLO was available in L. monocytogenes infection (Carrero et al., 2012). It is possible that different amounts of LLO were available for BMDMs or DCs or different surface receptors, explaining their differences in cytotoxicity. Therefore, we selected DCs as the vectors showing features of safe vaccines. We also searched for the most suitable L. monocytogenes antigen that triggered protective Th1 responses. Although CD8 ${ }^{+} \mathrm{T}$ cells recognize several epitopes, immunodominant CD8 epitopes are eluted from MHC-I molecules and associate with effector functions. Pathogen-specific $\mathrm{CD}^{+} \mathrm{T}$ cells play a major role in protection against listeriosis, but also pathogen-specific $\mathrm{CD} 4^{+} \mathrm{T}$ cells efficiently collaborate in conferring protective immunity (Skoberne and Geginat, 2002; Pamer, 2004; Nagata and Koide, 2010). To date, LLO has been revealed as the immunodominant antigen in listeriosis and the $\mathrm{CD}^{+}{ }^{+}$-specific $\mathrm{LLO}_{91-99}$ epitope is the major epitope eluted from MHC-I molecules, which confers protection (Kono et al., 2012). However, the $\mathrm{CD}^{+}{ }^{+}$-specific LLO $_{189-201}$ epitope also confers protection against listeriosis and appears as the major epitope eluted from MHC-II molecules (Geginat et al., 2001; Skoberne and Geginat, 2002). In this study, we presented the abilities of a novel L. monocytogenes antigen, GAPDH, which is a powerful antigen that triggers $\mathrm{T}$ cell responses in vivo (Álvarez-Domínguez et al., 2008 and this study in the hind foot pads). We also described the features of the $\mathrm{GAPDH}_{1-22}$ peptide that contained $\mathrm{CD}^{+}{ }^{+}$-specific and $\mathrm{CD} 4^{+}$-specific epitopes that were combined in DC vaccine vectors; DC-GAPDH ${ }_{1-22}$, confers protection against listeriosis with higher ratios than DC-LLO91-99 vectors. Several characteristics of $\mathrm{GAPDH}_{1-22}$ peptide make this long epitope attractive for vaccination purposes. $\mathrm{GAPDH}_{1-22}$ peptide was a strong binder to MHC-I and a weak binder to MHC-II molecules. This peptide contains at least two strong binding sequences to MHC-I molecules similar to $\mathrm{LLO}_{91-99}$ epitope, sequences $\mathrm{GAPDH}_{5-15}$ and $\mathrm{GAPDH}_{8-18}$. This peptide also shows two weak binding sequences to MHC-II molecules similar to $\mathrm{LLO}_{189-201}$ epitope, sequences $\mathrm{GAPDH}_{4-18}$ and $\mathrm{GAPDH}_{8-22}$. According to the $3 \mathrm{D}$ structure modeling, GAPDH $\mathrm{G}_{5-15}$ is localized in a loop similar to the 3D loop structure of $\mathrm{LLO}_{91-99}$ and $\mathrm{GAPDH}_{8-22}$ in the $\alpha$-helix structure that is shared by most MHC-II binding sequences, including $\mathrm{LLO}_{189-201}$. Combination of MHC-I and MHC-II binding epitopes might explain the ability of DC$\mathrm{GAPDH}_{1-22}$ vaccine vector to confer higher protection against 
listeriosis than DC-LLO ${ }_{91-99}$ vaccine vector can. It can also explain why DC-GAPDH ${ }_{1-22}$ vaccine vector elicited greater primary $\mathrm{T}$ cell responses since it can elicit both, $\mathrm{CD} 4^{+}$and $\mathrm{CD}^{+}$-restricted responses. However, DC-LLO $189-201$ and DC$\mathrm{LLO}_{91-99}$ vaccine vectors elicit only $\mathrm{CD}^{+}{ }^{+}$or $\mathrm{CD}^{+}$-restricted responses, respectively. Moreover, these results are also in agreement with studies indicating that $L$. monocytogenes-specific CD4 ${ }^{+}$ $\mathrm{T}$ cells played a role in protection against listeriosis, probably collaborating with immunodominant epitope-specific $\mathrm{CD}^{+} \mathrm{T}$ cells (Nagata and Koide, 2010). DC-GAPDH $1-22$ vaccine vectors produced higher IL-12 levels and frequencies of $\mathrm{GADPH}_{1-22}-$ restricted $\mathrm{CD}^{+} \mathrm{T}$ cells than the induction observed with the single $\mathrm{CD}^{+}$epitope DC-LLO91-99 vaccine vector. Production of IL-12 is related to anti-Listeria responses and with vaccine success (Kono et al., 2012; Lee et al., 2013). Therefore, it seems that DC designs containing $\mathrm{CD}^{+}$and $\mathrm{CD} 4^{+}$epitopes such as DC-GAPDH $H_{1-22}$ are effective vaccine vectors. Production of Th1 cytokines MCP-1, TNF- $\alpha$ and IFN- $\gamma$ and lack of production of Th2 cytokines such as IL-6 and IL-10, which are responsible for exaggerated inflammatory reactions and putative autoimmune responses in listeriosis, are features that are also relevant for protective DC vaccine vectors (Kono et al., 2012; Vacas-Cordoba et al., 2013).

In summary, the present study revealed a novel DC design, DC-GAPDH $H_{1-22}$, which confers greater protection against listeriosis than the previously described DC design, DC-LLO91-99. We conclude that DC-GAPDH $H_{1-22}$, which combines several $\mathrm{CD}^{+}$and $\mathrm{CD}^{+}$epitopes in a single vaccine vector, shows greater protection against listeriosis, because this DC vaccine increases the magnitude of primary $\mathrm{T}$ cell responses, the percentage of $\mathrm{GAPDH}_{1-22}$-restricted $\mathrm{CD}^{+} \mathrm{T}$ cells, and the levels of IL-12. Also, the phenotype of DC-GAPDH ${ }_{1-22}$ vaccine vector with higher expression of the maturation markers, CD80 and CD86, characteristic of polarized and IL-12-producing DCs (Kono et al., 2012) might also contribute to protective efficacy.

\section{ACKNOWLEDGMENTS}

We thank R. Tobes (Era7 Information Technologies SL. Granada. Spain) for the design of bioinformatics models. We are indebted to M. P. Lopez-Mato (Biodonosti Parque Tecnologico. San Sebastian. Spain) for the help with the frequencies of pathogenspecific $\mathrm{CD}^{+}{ }^{+} \mathrm{T}$ cells. We also acknowledge E. Rodriguez-Del Rio, L. Fernandez-Prieto, Alexandre Bosch-Martínez and L. AlvarezMontes for excellent technical assistance and J. C. Zabala (UC Santander) for laboratory support. This study was supported in part by the Spanish Secretary of State for Research and Innovation grants to Carmen Álvarez-Domínguez: BIO2002-0628, SAF200608968, SAF2009-08695, SAF2012-34203 and by the Fondo de Investigaciones Sanitarias grants to Eugenio Carrasco-Marín: PI/013128, PI/031009, PI/07028, PI/100660 and PI/131884. Grant SAF2012-34203 supports salaries of Alexandre Bosch-Martínez and Elisabet Frande-Cabanes. This study is held by Spanish patent reference 200602175(3) and the international extend patent, PCT/ES2007/070144 licensed to Fundación Marqués de Valdecilla and Carmen Álvarez-Domínguez and Eugenio Carrasco-Marín are the entitled authors.

\section{REFERENCES}

Álvarez-Domínguez, C., Madrazo-Toca, F., Fernandez-Prieto, L., Vandeckerhove, J., Pareja, E., Tobes, R., et al. (2008). Characterization of a Listeria monocytogenes protein interfering with Rab5a. Traffic 9, 325-337. doi: 10.1111/j.16000854.2007.00683.x

Álvarez-Domínguez, C., and Stahl, P. D. (1999). Increased expression of Rab5a correlates directly with accelerated maturation of Listeria monocytogenes phagosomes. J. Biol. Chem. 274, 11459-11462.

Bahjat, K. S., Meyer-Morse, N., Lemmens, E. E., Shugart, J. A., Dubensky, T. W., Brockstedt, D. G., et al. (2008). Suppression of cell-mediated immunity following recognition of phagosome-confined bacteria. PLoS Pathog. 5:e1000568. doi: 10.1371/journal.ppat.1000568

Brockstedt, D. G., Bahjat, K. S., Giedlin, M. A., Liu, W., Leong, M., Luckett, W., et al. (2005). Killed but metabolically active microbes: a new vaccine paradigm for eliciting effector T-cell responses and protective immunity. Nat. Med. 11, 853-860. doi: 10.1038/nm1276

Bruder, D., Nussbaum, A. K., Gakamsky, D. M., Schirle, M., Stevanovic, S., SinghJasuja, H., et al. (2005). Multiple synergizing factors contribute to the strength of the CD81 T cell response against listeriolysin O. Int. Immunol. 18, 89-100. doi: 10.1093/intimm/dxh352

Bruhn, K. W., Craft, N., and Miller, J. F. (2007). Listeria as vaccine vector. Microbes Infect. 9, 1226-1235. doi: 10.1016/j.micinf.2007.05.010

Carrasco-Marín, E., Fernández-Prieto, L., Rodriguez-Del Rio, E., Madrazo-Toca, F., Reinheckel, T., Saftig, P., et al. (2011). Limp-II links late phagosomal traficking with the onset of Listeria monocytogenes innate immunity: a role in macrophage activation. J. Biol. Chem. 286, 3332-3341. doi: 10.1074/jbc.M110. 146761

Carrasco-Marín, E., Madrazo-Toca, F., De los Toyos, J. R., Cacho-Alonso, E., Tobes, R., Pareja, E., et al. (2009). The innate immunity role of cathepsin-D is linked to Trp-491 and Trp-492 residues of listeriolysin O. Mol. Microbiol. 72, 668-682. doi: 10.1111/j.1365-2958.2009.06673.x

Carrasco-Marín, E., Rodriguez-Del Rio, E., Frande-Cabanes, E., Tobes, R., Pareja, E., Lecea-Cuello, M. J., et al. (2012). Phagosomes induced by cytokines function as anti-Listeria vaccines: a novel role for functional compartmentalization of Stat-1 and cathepsin-D. J. Biol. Chem. 287, 14310-14324. doi: 10.1074/jbc.M112.348615

Carrero, J., Vivanco-Cid, H., and Unanue, E. R. (2012). Listeriolysin O is strongly immunogenic independent of its cytotoxic activity. PLoS ONE 7:e32310. doi: 10.1371/journal.pone.0032310

Del Cerro-Vadillo, E., Madrazo-Toca, F., Carrasco-Marín, E., Fernandez-Prieto, L., Beck, C., Leyva-Cobián, F., et al. (2006). Cutting edge: a novel nonoxidative phagosomal mechanism exerted by cathepsin-D controls Listeria monocytogenes intracellular growth. J. Immunol. 176, 1321-1325.

Frande-Cabanes, E., Fernadez-Prieto, L., Calderon-Gonzalez, R., Rodriguez-Del Rio, E., Yañez-Diaz, S., Lopez-Fanarraga, M., et al. (2014). Dissociation of innate immune responses in microglia infected with Listeria monocytogenes. Glia 62, 233-246. doi: 10.1002/glia.22602

Geginat, G., Schenk, S., Skoberne, M., Goebel, W., and Hof, H. (2001). A novel approach of direct ex vivo epitope mapping identifies dominant and subdominant CD4 and CD8 T cell epitopes from Listeria monocytogenes. J. Immunol. $166,1877-1884$.

Kim, S. H., Castro, F., Paterson, Y., and Gravekamp, C. (2009). High efficiency of a Listeria-based vaccine against metastatic breast cancer reveals a dual mode of action. Cancer Res. 69, 5860-5866. doi: 10.1158/0008-5472.CAN-08-4855

Kim, Y., Ponomarenko, J., Zhu, Z., Tamang, D., Wang, P., Greenbaum, J., et al. (2012). Immune epitope database analysis resource. Nucleic Acids Res. 40, W525-W530. doi: 10.1093/nar/gks438

Kono, M., Nakamura, Y., Suda, T., Uchijima, M., Tsujimura, K., Nagata, T., et al. (2012). Enhancement of protective immunity against intracellular bacteria using type-1 polarized dendritic cell (DC) vaccine. Vaccine 30, 2633-2639. doi: 10.1016/j.vaccine.2012.02.026

Lauer, P., Hanson, B., Lemmens, E. E., Liu, W., Luckett, W. S., Leong, M. L., et al. (2008). Constitutive Activation of the PrfA regulon enhances the potency of vaccines based on live-attenuated and killed but metabolically active Listeria monocytogenes strains. Infect. Immun. 76, 3742-3753. doi: 10.1128/IAI.00390-08

Lee, S. H., Carrero, J. A., Uppaluri, R., White, J. M., Archambault, J. M., Lai, K. S., et al. (2013). Identifying the initiating events of anti-Listeria responses using mice with conditional loss of IFN- $\gamma$ receptor subunit 1 (IFNGR1). J. Immunol. 191, 4223-4234. doi: 10.4049/jimmunol.1300910 
Lundegaard, C., Lamberth, K., Harndahl, M., Buus, S., Lund, O., and Nielsen, M. (2008). NetMHC-3.0: accurate web accessible predictions of human, mouse, and monkey MHC class I affinities for peptides of length 8-11. Nucleic Acids Res. 36, W509-W512. doi: 10.1093/nar/gkn202

Martirosyan, A., Pérez-Gutierrez, C., Banchereau, R., Dutartre, H., Lecine, P., Dullaers, M., et al. (2012). Brucella $\beta$ 1,2 cyclic glucan is an activator of human and mouse dendritic cells. PLoS Pathog. 8:e1002983. doi: 10.1371/journal.ppat.1002983

Matsumura, F., Yamakita, Y., Starovoytov, V., and Yamashiro, N. (2013). Fascin confers resistance to Listeria infection in dendritic cells. J. Immunol. 191, 6156-6164. doi: 10.4049/jimmunol.1300498

Mohamed, W., Sethi, S., Tchatalbachev, S., Darji, A., and Chakraborty, T. (2012). Protective immunity to Listeria monocytogenes infection mediated by recombinant Listeria innocua harboring the VGC locus. PLoS ONE 7:e35503. doi: 10.1371/journal.pone.0035503

Nagata, T., and Koide, Y. (2010). Induction of specific CD8 T cells against intracellular bacteria by CD8 T cell-oriented immunization approaches. J. Biomed. Biotechnol. 2010:764542. doi: 10.1155/2010/764542

Nielsen, M., Lundegaard, C., Worning, P., Lauemøller, S. L., Lamberth, K., Buus, S., et al. (2003). Reliable prediction of T-cell epitopes using neural networks with novel sequence representations. Protein Sci. 12, 1007-1017. doi: 10.1110/ ps.0239403

Palucka, K., and Banchereau, J. (2013). Human dendritic cell subsets in vaccination. Curr. Opin. Immunol. 25, 396-402 doi: 10.1016/j.coi.2013.05.001

Pamer, E. G. (2004). Immune responses to Listeria monocytogenes. Nat. Rev. Immunol. 4, 812-823. doi: 10.1038/nri1461

Peters, B., and Sette, A. (2005). Generating quantitative models describing the sequence specificity of biological processes with the stabilized matrix method. BMC Bioinformatics 6:132. doi: 10.1186/1471-2105-6-132

Pion, M., Serramia, M. J., Diaz, L., Bryszewska, M., Gallart, T., Garcia, F., et al. (2010). Phenotype and functional analysis of human monocytes-derived dendritic cells loaded with a carbosilane dendrimer. Biomaterials 31, 8749-8758. doi: 10.1016/j.biomaterials. 2010.07.093

Portnoy, D. A., Auerbuch, V., and Glomski, I. J. (2002). The cell biology of Listeria monocytogenes infection: the intersection of bacterial pathogenesis and cell-mediated immunity. J. Cell Biol. 158, 409-414. doi: 10.1083/jcb.200 205009

Prada-Delgado, A., Carrasco-Marin, E., Bokoch, G. M., and Álvarez-Domínguez, C. (2001). Interferon-gamma listericidal action is mediated by novel Rab5a functions at the phagosomal environment. J. Biol. Chem. 276, 19059-19065. doi: 10.1074/jbc.M101639200

Quispe-Tintaya, W., Chandra, D., Jahangir, A., Harris, M., Casadevall, A., Dadachova, E., et al. (2013). Nontoxic radioactive Listeriaat is a highly effective therapy against metastatic pancreatic cancer. Proc. Natl. Acad. Sci. U.S.A. 110, 8668-8673. doi: 10.1073/pnas.1211287110

Rodriguez-Del Rio, E., Frande-Cabanes, E., Tobes, R., Pareja, E., Lecea-Cuello, M. J., Ruiz-Saez, M., et al. (2011). The intact structural form of LLO in endosomes cannot protect against listeriosis. Int. J. Biochem. Mol. Biol. 2, 207-218.

Sashinami, H., Nakane, A., Iwakura, Y., and Sasaki, M. (2003). Effective induction of acquired resistance to Listeria monocytogenes by immunizing mice with in vivo-infected dendritic cells. Infect. Immun. 71, 117-125. doi: 10.1128/IAI.71.1.117-125.2003

Sharma, N., and Agrewala, J. N. (2004). Potent role of vaccines prepared from macrophages infected with live bacteria in protection against Mycobacterium tuberculosis and Salmonella typhimurium infections. J. Infect. Dis. 190, 107-114. doi: 10.1086/421116

Sidney, J., Assarsson, E., Moore, C., Ngo, S., Pinilla, C., Sette, A., et al. (2008). Quantitative peptide binding motifs for 19 human and mouse MHC class I molecules derived using positional scanning combinatorial peptide libraries. Immunome. Res. 4:2. doi: 10.1186/1745-7580-4-2

Sijts, A. J., Villanueva, M. S., and Pamer, E. G. (1996). CTL epitope generation is tightly linked to cellular proteolysis of a Listeria monocytogenes antigen. J. Immunol. 156, 1497-1503.

Singh, V., Jain, S., Gowthaman, U., Parihar, P., Gupta, P., Gupta, U. D., et al. (2011). Co-administration of IL-1+IL-6+TNF-a with Mycobacterium tuberculosis infected macrophages vaccine induces better protective $\mathrm{T}$ cell memory than BCG. PLoS ONE 6:e16097. doi: 10.1371/journal.pone.0016097

Skoberne, M., and Geginat, G. (2002). Efficient in vivo presentation of Listeria monocytogenes derived CD4 and CD8 cell epitopes in the absence of IFN- $\gamma$. J. Immunol. 168, 1854-1860.

Starks, H., Bruhn, K. W., Shen, H., Barry, R. A., Dubensky, T. W., Brockstedt, D., et al. (2004). Listeria monocytogenes as a vaccine vector: virulence attenuation or existing antivector immunity does not diminish therapeutic efficiency. J. Immunol. 173, 420-437.

Vacas-Cordoba, E., Pion, M., Rasines, B., Filippini, D., Komber, H., Ionov, M., et al. (2013). Glycodendrimers as new tools in the search for effective anti-HIV DC-based immunotherapies. Nanomedicine 9, 972-984. doi: 10.1016/j.nano.2013.03.004

Yu, C. I., Becker, C., Wang, Y., Marches, F., Helft, J., Leboeuf, M., et al. (2013). Human CD1c+ dendritic cells drive the differentiation of CD103+ CD8+ mucosal effector $\mathrm{T}$ cells via the cytokine TGF- $\beta$. Immunity $18,818-830$. doi: 10.1016/j.immuni.2013.03.004

Ziegler, K., and Unanue, E. R. (1981). Identification of a macrophage antigenprocessing event required for I-region-restricted antigen presentation to $\mathrm{T}$ lymphocytes. J. Immunol. 127, 1869-1875.

Conflict of Interest Statement: This study is hold by Spanish patent 200602175(3) and the international extend PCT/ES2007/070144. These patents are licensed to Fundación Marqués de Valdecilla and the authors are Carmen Álvarez-Domínguez and Eugenio Carrasco-Marín. The authors declare that the research was conducted in the absence of any commercial or financial relationships that could be construed as a potential conflict of interest.

Received: 30 November 2013; accepted: 05 February 2014; published online: 21 February 2014.

Citation: Calderón-González R, Frande-Cabanes E, Bronchalo-Vicente L, LeceaCuello MJ, Pareja E, Bosch-Martínez A, Fanarraga ML, Yañez-Díaz S, CarrascoMarín E and Álvarez-Domínguez C (2014) Cellular vaccines in listeriosis: role of the Listeria antigen GAPDH. Front. Cell. Infect. Microbiol. 4:22. doi: 10.3389/fcimb. 2014.00022

This article was submitted to the journal Frontiers in Cellular and Infection Microbiology.

Copyright () 2014 Calderón-González, Frande-Cabanes, Bronchalo-Vicente, LeceaCuello, Pareja, Bosch-Martínez, Fanarraga, Yañez-Díaz, Carrasco-Marín and Álvarez-Dominguez. This is an open-access article distributed under the terms of the Creative Commons Attribution License (CC BY). The use, distribution or reproduction in other forums is permitted, provided the original author(s) or licensor are credited and that the original publication in this journal is cited, in accordance with accepted academic practice. No use, distribution or reproduction is permitted which does not comply with these terms. 